\title{
Using compositional mixed-effects models to evaluate responses to amino acid supplementation in milk replacers for calves
}

\author{
M. Terré, ${ }^{1 *} \odot$ I. Ortuzar, ${ }^{2} \odot$ J. Graffelman, ${ }^{2} \odot$ A. Bassols, ${ }^{3} \odot$ M. Vidal, ${ }^{1}$ and A. Bach $^{1,4} \oplus$ \\ ${ }^{1}$ Department of Ruminant Production, IRTA (Institut de Recerca i Tecnologia Agroalimentàries), 08140 Caldes de Montbui, Spain \\ ${ }^{2}$ Department of Statistics and Operation Research, Universitat Politècnica de Catalunya, 08034 Barcelona, Spain \\ ${ }^{3}$ Departament de Bioquímica i Biologia Molecular, Facultat de Veterinària, Universitat Autònoma de Barcelona Cerdanyola del Vallès, \\ 08193 Barcelona, Spain \\ ${ }^{4}$ ICREA (Institució Catalana de Recerca i Estudis Avançats), 08010 Barcelona, Spain
}

\section{ABSTRACT}

The consequences of supplementing Lys, Met, and Thr in milk replacers (MR) for calves have been widely studied, but scarce information exists about potential roles of other AA (whether essential or not). The effects on growth performance of supplementation of 4 different AA combinations in a mixed ration $(25.4 \%$ crude protein and $20.3 \%$ fat) based on skim milk powder and whey protein concentrate were evaluated in 76 Holstein male calves $(3 \pm 1.7 \mathrm{~d}$ old $)$. The $4 \mathrm{MR}$ were as follows: CTRL with no AA supplementation; PG, supplying additional $0.3 \%$ Pro and $0.1 \%$ Gly; FY, supplying additional $0.2 \%$ Phe and $0.2 \%$ Tyr; and KMT, providing additional $0.62 \%$ Lys, $0.22 \%$ Met, and $0.61 \%$ Thr. All calves were fed the same milk allowance program and were weaned at $56 \mathrm{~d}$ of study. Concentrate intake was limited to minimize interference of potential differences in solid feed intake among treatments. Animals were weighed weekly, intakes recorded daily, and blood samples obtained at 2, 5, and 7 wk of study to determine serum urea and plasma AA concentrations. Plasma AA concentrations were explored using compositional data analysis, and their isometric log-ratio transformations were used to analyze their potential influence on ADG and serum urea concentration using a linear mixed-effects model. We detected no differences in calf performance and feed intake. Plasma relative concentration of the AA supplemented in the KMT and PG treatments increased in their respective treatments, and, in PG calves, a slight increase in the proportion of plasma Gly, Glu, and branched-chain AA was also observed. The proportions of plasma branched-chain AA, His, and Gln increased, and those of Thr, Arg, Lys, and Glu decreased with calves' age. A specific log-contrast

Received December 13, 2020.

Accepted March 9, 2021.

*Corresponding author: marta.terre@irta.cat balance formed by Arg, Thr, and Lys was found to be the main driver for lowering serum urea concentrations and increasing calf growth. The use of compositional mixed-effects models identified a cluster formed by the combination of Arg, Thr, and Lys, as a potential AA to optimize calf growth.

Key words: amino acid, calf growth, compositional data analysis

\section{INTRODUCTION}

Newborn dairy calves are usually separated from their mothers at birth, and after 2 or 3 colostrum or transition milk feedings, they are fed either milk replacer (MR), saleable milk, or waste milk. A recent report (Urie et al., 2018) showed that the whole or waste milk was the most $(\sim 40 \%)$ common liquid feed used in the United States, with 35\% feeding MR and the rest a combination of MR and whole or waste milk. Although MR attempts to replace whole milk (WM), its nutritional composition differs considerably from that of WM, which is commonly richer in protein and fat than MR. In recent years, the tendency in the MR industry has been to increase the $\mathrm{CP}$ and decrease fat content of MR, but AA composition of MR, which depends in part on the protein sources used in MR formulation, has received little attention. Some studies (Hill et al., 2008; Castro et al., 2016; Chagas et al., 2018) involving young calves $(<80 \mathrm{~kg})$ have suggested that supplementation of limiting AA might improve $\mathrm{N}$ utilization. For example, Hill et al. (2008) suggested that MR should supply $2.34 \%$ Lys, $0.72 \%$ Met, and $1.8 \%$ Thr to maximize ADG and feed efficiency, and Bai et al. (2020), following these suggestions, reported an economic benefit with an MR containing $22 \% \mathrm{CP}$ and complying with the previously listed AA indications, compared with an MR containing $24 \% \mathrm{CP}$ without achieving Lys and Met levels reported in Hill et al. (2008).

Whole milk has 2 protein fractions: $\sim 82 \%$ are caseins and $\sim 17 \%$ whey proteins, and both differ in their AA 
profile (Ceballos et al., 2009). Existing MR differ in their ingredient composition and in their AA profile (Hill et al., 2007, 2008; Morrison et al., 2017); therefore, their availability in the intestine due to abomasum curd formation (Yvon et al., 1985), or to the regulation of intestinal AA transport (Bhutia and Ganapathy, 2018), can vary greatly. For instance, Phe and Tyr (formed from Phe) are 30 and $46 \%$ greater in WM than in the all-whey protein MR used in Hill et al. (2008), respectively; and proportions of Lys and Met previously evaluated by Hill et al. (2008) are also present in lesser concentrations in the all-whey basal MR compared with WM. Other, nonessential AA, such as Pro and Gly are also in lesser proportions in MR than in WM, and these 2 AA participate in systematic functions such as cell signaling, gene expression, and metabolic regulation (Wu et al., 2014), and they are the main contributors to collagen formation, which is critical to sustain growth (Li and $\mathrm{Wu}, 2018$ ).

Proteins have a unique linear AA sequence, and AA bioavailabilities are linked to one another for protein synthesis (Regmi et al., 2016). Amino acids are absorbed in the intestine and then used by different tissues of the organism for different biological functions. Amino acid excess will be metabolized in the liver through the urea cycle and most of the carbon skeletons used as energy sources (Brosnan, 2003). The metabolic flow of AA among tissues and organs is affected by diverse factors (plane of nutrition, physiological state, diseases, and more), and it is ultimately reflected in the plasma AA profile (Shikata et al., 2007). Then, to some extent, the plasma AA profile that maximizes growth may help to determine the adequate AA dietary profile (Wu, 2014). The mixture of AA in plasma can be evaluated as a compositional vector, where the components cannot be interpreted in isolation without considering their interdependencies. Compositional data consist of data vectors containing relative information on the parts of some whole. Plasma AA concentrations may be regarded as compositional data, because they are measured with respect to a reference volume. Compositional data analysis has a longstanding tradition in geology, where mineral concentrations in rock samples have long been regarded as compositional and analyzed using the log-ratio approach (Aitchison, 1986). Similarly, AA concentrations can be seen as compositional and analyzed with the log-ratio methodology. Amino acids in blood samples show large differences in concentrations, where concentrations of Gly are easily 10 times as large as those of Met. A small change in a concentration may thus represent a minor relative change in the concentration of Gly but a bold relative change for Met. This indicates that ratios of concentrations may actually be more informative than differences of concentrations, and that a compositional approach is called for. In fact, in human medicine, several plasma AA ratios have been described for the diagnosis of metabolic diseases (Kimura et al., 2009). To date, most of the literature analyzing the relationship between animal growth and AA profile of feeds have ignored these characteristics of AA (Morrison et al., 2017; Chagas et al., 2018), and those studies that performed plasma AA determinations (Rius et al., 2012; Ahangarani et al., 2020) have analyzed the different AA independently of one another using ANOVA or linear regressions. In general, a compositional data analysis-based approach is based on the analysis of relative information (ratios), and it can lead to different conclusions than a standard statistical analysis.

Therefore, the hypothesis of this study was that formulating MR with different AA combinations, with a closer profile to that found in WM, may improve calf performance, and the use of compositional data analysis would help to better understand the importance of AA to sustain growth. The objective of the present study was to determine whether treating changes in plasma AA profile as a compositional vector may help us to understand the influence of AA on growth performance and protein utilization.

\section{MATERIALS AND METHODS}

\section{Animals and Feeding Program}

Seventy-six male Holstein newborn calves $(3 \pm 1.7 \mathrm{~d}$ of age and $43.4 \pm 6.38 \mathrm{~kg}$ of BW) from a single farm were enrolled in this study between December 2016 and March 2017 and raised in the facilities of Institut de Recerca i Tecnologia Agroalimentàries (IRTA) at Torre Marimon (Caldes de Montbui, Spain). Within the first $6 \mathrm{~h}$ of life, calves received $3.5 \mathrm{~L}$ of colostrum with a minimum of $23{ }^{\circ}$ Brix (previously thawed). Calves were blocked by arrival date at the research facilities and randomly distributed into 4 treatments following a randomized complete block design. Calves were managed under common rearing conditions under the supervision of IRTA technicians and the approval of the Animal Care Committee of the Government of Catalonia (authorization code 9733 ). Calves were individually housed in indoor pens $(1 \times 1.6 \mathrm{~m})$ equipped with one bucket for water, one for concentrate, and one for forage. Pens were bedded with sawdust on a daily basis, and calves were bottle-fed MR. Once moved to the research facilities, calves had ad libitum access to water and chopped barley straw (2.4\% CP, 87.7\% NDF, $59.6 \%$ ADF, on a DM basis). Straw was chopped using a forage chopper 
Table 1. Ingredient and chemical composition (\% of DM) of milk replacers for the different treatments, and starter concentrate and straw used as common feeds for all treatments ${ }^{1}$

\begin{tabular}{|c|c|c|c|c|c|c|}
\hline \multirow[b]{2}{*}{ Item } & \multicolumn{4}{|c|}{ Milk replacer } & \multirow[b]{2}{*}{ Concentrate } & \multirow[b]{2}{*}{ Straw } \\
\hline & CTRL & PG & FY & KMT & & \\
\hline \multicolumn{7}{|l|}{ Ingredient, \% } \\
\hline Barley & & & & & 16.5 & \\
\hline Corn & & & & & 30.0 & \\
\hline Wheat & & & & & 15.0 & \\
\hline Soybean meal & & & & & 21.4 & \\
\hline Soybean hulls & & & & & 1.04 & \\
\hline Wheat bran & & & & & 13.1 & \\
\hline Calcium carbonate & & & & & 1.20 & \\
\hline Dicalcium phosphate & & & & & 0.70 & \\
\hline Magnesium oxide & & & & & 0.05 & \\
\hline Sodium chloride & & & & & 0.80 & \\
\hline Micromineral vitamin premix & & & & & 0.20 & \\
\hline Skim milk powder & 39 & 40 & 40 & 40 & - & - \\
\hline Whey protein concentrate 35 & 15 & 15 & 15.7 & 15.6 & - & - \\
\hline Whey protein concentrate 60 & 4 & 2.6 & 2.05 & 0.95 & - & - \\
\hline Fatted whey & 39 & 39 & 38.85 & 39 & - & - \\
\hline Mineral and vitamin premix ${ }^{2}$ & 3 & 3 & 3 & 3 & - & - \\
\hline $\mathrm{L}-\mathrm{Pro}^{3}$ & - & 0.3 & - & - & - & - \\
\hline $\mathrm{Gly}^{3}$ & - & 0.1 & - & - & - & - \\
\hline L-Phe ${ }^{3}$ & - & - & 0.2 & - & - & - \\
\hline L-Tyr ${ }^{3}$ & - & - & 0.2 & - & - & - \\
\hline L-Lys ${ }^{3}$ & - & - & - & 0.62 & - & - \\
\hline L-Met ${ }^{3}$ & - & - & - & 0.22 & - & - \\
\hline L-Thr ${ }^{3}$ & - & - & - & 0.61 & - & - \\
\hline \multicolumn{7}{|l|}{ Chemical composition \% of DM } \\
\hline DM & 97.9 & 97.4 & 98.1 & 98.0 & 87.7 & 83.8 \\
\hline $\mathrm{CP}$ & 25.4 & 25.5 & 25.1 & 25.4 & 19.3 & 3.8 \\
\hline Fat & 20.2 & 20.4 & 20.2 & 20.2 & 3.0 & - \\
\hline Lactose & 44.8 & 45.4 & 45.6 & 44.4 & - & - \\
\hline Ash & 7.0 & 7.3 & 7.0 & 6.9 & 5.7 & 6.4 \\
\hline $\mathrm{ADF}$ & - & - & - & - & 6.4 & 52.9 \\
\hline $\mathrm{NDF}$ & - & - & - & - & 16.9 & 79.7 \\
\hline $\mathrm{ME},{ }^{4} \mathrm{Mcal} / \mathrm{kg}$ & 4.82 & 4.82 & 4.82 & 4.82 & 3.05 & 1.23 \\
\hline
\end{tabular}

${ }^{1} \mathrm{CTRL}=$ milk replacer $(\mathrm{MR})$ with no AA supplementation; PG $=$ MR supplying additional $0.3 \%$ Pro and $0.1 \%$ Gly; FY $=$ MR supplying additional $0.2 \%$ Phe and $0.2 \%$ Tyr; KMT $=$ MR providing additional $0.62 \%$ Lys, $0.22 \%$ Met, and $0.61 \%$ Thr.

${ }^{2}$ Mineral and vitamin composition: vitamin A 25,000 IU $/ \mathrm{kg}$; vitamin $\mathrm{D}_{3} 4,500 \mathrm{IU} / \mathrm{kg}$; vitamin E $300 \mathrm{mg} / \mathrm{kg}$, vitamin C $300 \mathrm{mg} / \mathrm{kg}$, vitamin $\mathrm{B}_{1} 16 \mathrm{mg} / \mathrm{kg}$, vitamin $\mathrm{B}_{2} 10 \mathrm{mg} / \mathrm{kg}$, vitamin $\mathrm{B}_{6} 10 \mathrm{mg} / \mathrm{kg}$, vitamin $\mathrm{B}_{12} 80 \mathrm{mg} / \mathrm{T}$, vitamin K $5.5 \mathrm{mg} / \mathrm{kg}$, folic acid $1 \mathrm{mg} / \mathrm{kg}$, pantothenic acid $23 \mathrm{mg} / \mathrm{kg}$, niacin $50 \mathrm{mg} / \mathrm{kg}$, iron $150 \mathrm{mg} / \mathrm{kg}$, zinc $170 \mathrm{mg} / \mathrm{kg}$, copper $10 \mathrm{mg} / \mathrm{kg}$, manganese $40 \mathrm{mg} / \mathrm{kg}$, iodine $1.3 \mathrm{mg} / \mathrm{kg}$, selenium $0.4 \mathrm{mg} / \mathrm{kg}$.

${ }^{3}$ Unprotected AA from Livzon Group (Fuxing Pharmaceutical Co.).

${ }^{4}$ Estimated according to NRC (2001) equations.

(Seco) to reach the following particle size distribution: $84.9 \%>20 \mathrm{~mm}, 7.0 \%$ between 8 and $20 \mathrm{~mm}$, and $8.1 \%$ $<8 \mathrm{~mm}$, according to Penn State Particle Separator. The amount of a pelleted starter feed $(19.3 \% \mathrm{CP}, 16.9 \%$ NDF, 6.4\% ADF, 5.7 ash, 3.0\% fat, on a DM basis) that was offered to calves was restricted to homogenize the effect of starter concentrate intake on calves' metabolism and minimizing interference with the nutrients (and AA) supplied by MR. The restriction was as follows: from d 1 to 17 , calves were offered a maximum of $100 \mathrm{~g}$ of starter concentrate; from 18 to $21 \mathrm{~d}, 200$ $\mathrm{g} / \mathrm{d}$; from 22 to $24 \mathrm{~d}, 300 \mathrm{~g} / \mathrm{d}$; from 25 to $28 \mathrm{~d}, 400$ $\mathrm{g} / \mathrm{d}$; from 29 to $31 \mathrm{~d}, 500 \mathrm{~g} / \mathrm{d}$; d 32 and $33,600 \mathrm{~g} / \mathrm{d} ; \mathrm{d}$ 34, $700 \mathrm{~g} / \mathrm{d} ; \mathrm{d} 35,800 \mathrm{~g} / \mathrm{d}$; from 36 to $38 \mathrm{~d}, 1,000 \mathrm{~g} / \mathrm{d}$; from 39 to $49 \mathrm{~d}, 1,300 \mathrm{~g} / \mathrm{d}$; thereafter fed ad libitum. Calves were fed $2 \mathrm{~L}$ of MR (25.4\% CP and $20.2 \%$ fat; Nukamel; Table 1) twice a day containing $12.5 \%$ MR powder $(500 \mathrm{~g} / \mathrm{d})$ for the first $4 \mathrm{~d}$; subsequently MR was increased to $5 \mathrm{~L} / \mathrm{d}$ of $\mathrm{MR}$ at $12.5 \%(625 \mathrm{~g} / \mathrm{d})$ for the next $3 \mathrm{~d}$, and then 2 meals of $3 \mathrm{~L}$ at $15 \%(900 \mathrm{~g} / \mathrm{d})$ until $49 \mathrm{~d}$ of age. Then, MR was limited to a single offer of $3 \mathrm{~L}$ also at $15 \%(450 \mathrm{~g} / \mathrm{d})$ until d 56, when calves were fully weaned.

\section{Milk Replacer Treatments}

Calves were randomly assigned to 1 of $4 \mathrm{MR}$ treatments containing different AA combinations. The AA 
Table 2. Amino acid composition (\% of DM) of milk replacers for the different treatments ${ }^{1}$ and starter concentrate

\begin{tabular}{lccccc}
\hline AA profile & CTRL & PG & FY & KMT & Concentrate \\
\hline DL-Asp & 2.17 & 2.07 & 2.14 & 2.10 & 1.55 \\
DL-Glu & 4.89 & 4.93 & 4.87 & 4.82 & 3.33 \\
DL-Ser & 1.32 & 1.25 & 1.29 & 1.29 & 0.85 \\
DL-His & 0.53 & 0.52 & 0.55 & 0.52 & 0.41 \\
Gly & 0.53 & 0.62 & 0.50 & 0.51 & 0.76 \\
DL-Thr & 1.37 & 1.30 & 1.36 & 1.75 & 0.70 \\
DL-Arg & 0.74 & 0.76 & 0.77 & 0.76 & 1.17 \\
DL-Alanine & 0.93 & 0.87 & 0.90 & 0.91 & 0.79 \\
DL-Tyr & 0.87 & 0.86 & 1.02 & 0.90 & 0.58 \\
DL-Val & 1.49 & 1.47 & 1.48 & 1.44 & 0.77 \\
DL-Met & 0.53 & 0.49 & 0.50 & 0.67 & 0.21 \\
DL-Phe & 0.96 & 0.95 & 1.20 & 0.97 & 0.82 \\
DL-Ile & 1.32 & 1.30 & 1.32 & 1.28 & 0.66 \\
DL-Leu & 2.45 & 2.35 & 2.38 & 2.36 & 1.35 \\
DL-Lys & 2.22 & 1.92 & 1.98 & 2.49 & 1.06 \\
DL-Hyp & $<0.030$ & $<0.030$ & $<0.030$ & $<0.030$ & 0.043 \\
DL-Pro & 2.00 & 2.32 & 2.03 & 1.92 & 1.05 \\
DL-Trp & 0.33 & 0.33 & 0.34 & 0.36 & 0.19 \\
\hline
\end{tabular}

${ }^{1} \mathrm{CTRL}=$ milk replacer $(\mathrm{MR})$ with no AA supplementation; $\mathrm{PG}=\mathrm{MR}$ supplying additional $0.3 \%$ Pro and $0.1 \%$ Gly; FY $=$ MR supplying additional $0.2 \%$ Phe and $0.2 \%$ Tyr; KMT $=$ MR providing additional $0.62 \%$ Lys, $0.22 \%$ Met, and $0.61 \%$ Thr.

used to supplement MR were obtained from Livzon Group (Fuxing Pharmaceutical Co. Ltd.). The 4 MR were formulated to be isonitrogenous and isoenergetic, replacing whey protein concentrate by the AA mixture supplemented in each treatment (Table 1). Treatments were identified by colors, and research personnel were blinded to the relation of colors and AA compositions, which were as follows: control treatment (CTRL) without additional AA supplementation; Pro and Gly treatment $(\mathbf{P G})$, providing an additional $0.3 \%$ Pro and $0.1 \%$ Gly in the MR formula; Phe and Tyr treatment (FY), supplying additional $0.2 \%$ Phe and $0.2 \%$ Tyr in the MR formula; and Lys, Met, and Thr treatment (KMT), providing an additional $0.62 \%$ Lys, $0.22 \%$ Met, and $0.61 \%$ Thr in the MR formula. Amino acid profiles of MR and starter concentrate are depicted in Table 2.

\section{Measurements}

Calves were weighed using an electronic scale (Mobba SC-01) at farm arrival and on a weekly basis thereafter. Individual MR and solid feed consumption (pellet and straw) were determined daily by measuring leftovers. Daily scores for both digestive and respiratory health status were recorded, being 1 for animals without disorders, 2 for animals with moderate symptoms, and 3 for animals with severe symptoms.

At 14, 35, and $49 \mathrm{~d}$ from the beginning of the study, blood samples were obtained from the jugular vein $4 \mathrm{~h}$ after the MR morning feeding at $0730 \mathrm{~h}$, using 20 -gauge needles and 10-mL Vacutainer tubes with lithium heparin or without additives (BD Diagnostics), and kept refrigerated until being centrifuged at $1,500 \times g$ for $10 \mathrm{~min}$ at room temperature and stored in aliquots at $-20^{\circ} \mathrm{C}$ until subsequent plasma $\mathrm{AA}$ and serum urea analyses.

\section{Chemical Analysis}

Feeds were analyzed for DM $\left(4 \mathrm{~h}\right.$ at $\left.103^{\circ} \mathrm{C}\right)$ and ash $\left(550^{\circ} \mathrm{C}\right.$ calcination), and for $\mathrm{CP}$ with a Kjeldahl automatic distiller (Kjeltec Auto 1030 Analyzer, Tecator), with copper sulfate/selenium as a catalyst instead of copper sulfate/titanium dioxide (method 988.05; AOAC International, 2000). Analysis for NDF was performed using sodium sulfite and heat-stable $\alpha$-amylase (Van Soest et al., 1991), and ADF was analyzed following (Robertson and Van Soest, 1981). Ether extract was analyzed following method 920.39 from AOAC International (1999) with petroleum ether instead of diethyl ether (AOAC International, 2000), with a previous acid hydrolysis. Total AA and total Trp concentrations were determined using fluorescence-HPLC and UV-HPLC, respectively, after a strong acid hydrolyzation with OPA and Fmoc (UNE, 2005a,b).

Serum urea concentration was performed with an Olympus AU400 analyzer using the Olympus System Reagent. Plasma AA were measured by HPLC as described by Yu et al. (2018), using an Elite LaChrom (Hitachi) equipped with a UV detector (Hitachi L-24200) with a Novapak C18 column $(300 \times 3.9 \mathrm{~mm})$ from Wa- 
ters. EZChrom Elite system V3.1.7 software (Agilent) was used for system control and data acquisition. The AA pairs formed by Ser and Asn and His and Gln could not be distinguished in the chromatogram, and their plasma concentrations were presented together as Ser. Asn and His.Gln, respectively.

\section{Statistical Analysis}

Outliers were checked using JMP 14.2.0 (2018, SAS Institute Inc.), and outlier boxplots were considered. Performance and intake data were analyzed using a mixed-effects model accounting for the fixed effects of AA supplementation in the MR, week of study, and their 2-way interaction, plus the random effect of calf using SAS 9.4 (2018, SAS Institute Inc.). Time entered the model as a repeated measure using an autoregressive variance-covariance matrix. Initial BW was used as covariate and enrollment date as a block, both entering the model as fixed effects.

For the compositional analysis of plasma AA concentrations, data were analyzed using $\mathrm{R}$ ( $\mathrm{R}$ Core Team, 2020) and using the composition library (version 1.405) for AA and the nlme library (version 3.1.140) for fitting mixed-effects models. A similar approach was used by Palarea-Albaladejo et al. (2017) with methane emissions and ruminal volatile fatty acids. First, data were explored by analyzing descriptive statistics, constructing a correlation matrix, and running a principal component analysis (PCA) among ADG, feed intake, incidence of diarrhea (defined as number of days that calf suffered from diarrhea per week), initial BW, initial age, and serum urea concentration. Then, plasma AA concentrations were explored using compositional data descriptive statistics (Aitchison, 1986) and analyzing the codependence structure of centered logratio-transformed AA through a biplot to determine the AA that contributed most to the total variance of the data, the AA that contributed to identify the different treatments, and those that changed through the different weeks of the study. This analysis allowed us to combine the components (i.e., amino acids) with low variance values using geometric means. Next, hierarchical clustering was performed using Ward's agglomerative method, and the AA variation matrix of every log-ratio pair (Table 3) was used as a measure of similarity between the components to construct a dendrogram (Figure 1), allowing us to reduce the initial composition of 16 AA (Asn.Ser, Glu, Gly, His.Gln, Arg, Thr, Ala, Pro, Tyr, Val, Met, Lys, Ile, Leu, Phe, and Trp) into a set of 10 components. Then, this simplified composition of plasma AA was clustered using Ward's method, and its variation matrix was used as the input distance matrix to obtain a useful isometric log-ratio transformation with reasonably interpretable coefficients, in which each agglomeration step was used to encode the corresponding balances depicted in Table 4. Then, a sign matrix was constructed, in which the components merging into a group were coded as +1 or -1 , indicating whether the component belonged to the first or second subgroup, and those not coded as 0 . Last, the balance matrix was built as the weighted log-ratio of the geometric means of the 2 groups:

$$
b_{k}=\sqrt{\frac{r s}{r+s}} \ln \frac{\left(x_{i 1}, x_{i 2}, \ldots, x_{i r}\right)^{1 / r}}{\left(x_{j 1}, x_{j 2}, \ldots, x_{j s}\right)^{1 / s}},
$$

where $x_{i 1}, x_{i 2}, \ldots, x_{i r}$ represent the parts of the +1 group and $x_{j 1}, \mathrm{x}_{\mathrm{j} 2}, \ldots, x_{j s}$ the parts of the -1 group, $r$ is the number of parts of the +1 group, and $s$ is the number of parts of the -1 group.

Growth performance and serum urea concentration of individual data were analyzed with a linear mixed-effects model (Pinheiro and Bates, 2000) with a random intercept to account for correlations between measurements made on the same calf, and considering milk and solid feed intake, week of study, days with diarrhea, initial age, initial BW, type of MR (or treatment), and the previously calculated isometric log-ratio coordinates (balances) as fixed effects. The final model excluded nonsignificant isometric log-ratio coordinates, but variables of biological interest used in the PCA (i.e., milk and feed intake, AA treatment supplementation, days with diarrhea, and week of study) were kept in the model, irrespective of their statistical significance. The individual random coefficient was tested for both dependent variables.

\section{RESULTS}

Two animals were removed from the study due to a leg injury and an initial $\mathrm{BW}<30 \mathrm{~kg}$. After removing these 2 animals, no other outliers were found using the outlier boxplots. Then, the study was conducted with 19 calves in the CTRL and FY treatments and 18 calves in the KMT and PG treatments.

\section{Performance Data}

We detected no differences in performance (844 \pm $22.3 \mathrm{~g} / \mathrm{d}$ of BW growth $)$, feed intake $(646 \pm 36.4 \mathrm{~g} / \mathrm{d}$ of concentrate feed intake), or feed efficiency (0.62 \pm 0.001) among the different MR treatments (Supplemental Table S1, https://doi.org/10.34810/data40). The 
Terré et al.: AMINO ACIDS IN MILK REPLACER

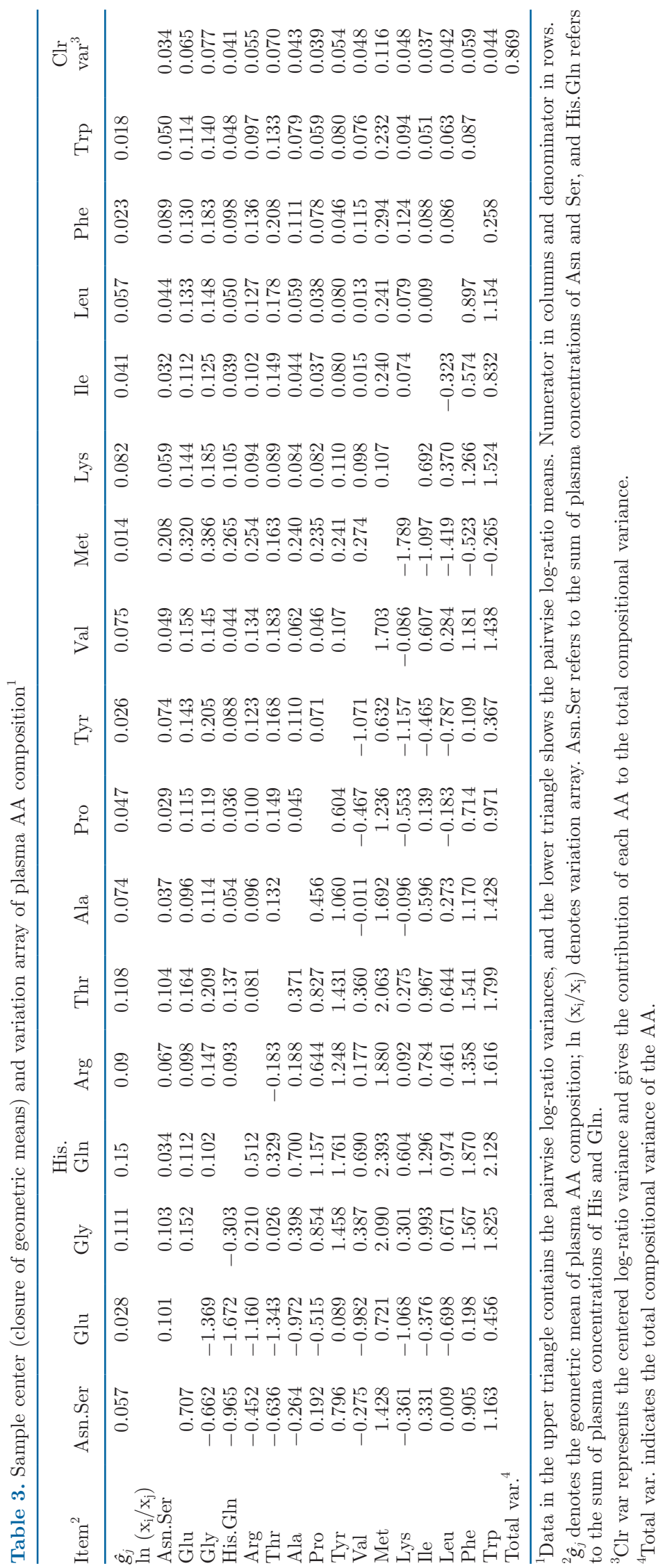


Table 4. Interpretation of balances resulting from the compositional analysis of plasma AA concentrations from calves fed milk replacers differing in AA composition

\begin{tabular}{ll}
\hline Balance & Interpretation $^{1}$ \\
\hline$b_{1}$ & $(\mathrm{G} 3)$ vs. $(\mathrm{G} 1)$ \\
$b_{2}$ & $(\mathrm{G} 3 \times \mathrm{G} 1)$ vs. $(\mathrm{Trp})$ \\
$b_{3}$ & $(\mathrm{G} 3 \times \mathrm{G} 1 \times \mathrm{Trp})$ vs. $(\mathrm{G} 2)$ \\
$b_{4}$ & $(\mathrm{Thr})$ vs. $(\mathrm{Arg})$ \\
$b_{5}$ & $(\mathrm{Thr} \times \mathrm{Arg})$ vs. $(\mathrm{Lys})$ \\
$b_{6}$ & $(\mathrm{G} 3 \times \mathrm{G} 1 \times \mathrm{Trp} \times \mathrm{G} 2)$ vs. $(\mathrm{Glu})$ \\
$b_{7}$ & $(\mathrm{G} 3 \times \mathrm{G} 1 \times \mathrm{Trp} \times \mathrm{G} 2 \times \mathrm{Glu})$ vs. $(\mathrm{Gly})$ \\
$b_{8}$ & $(\mathrm{G} 3 \times \mathrm{G} 1 \times \mathrm{Trp} \times \mathrm{G} 2 \times \mathrm{Glu} \times \mathrm{Gly})$ \\
$b_{9}$ & vs. $(\mathrm{Thr} \times \mathrm{Arg} \times \mathrm{Lys})$ \\
\hline
\end{tabular}

${ }^{1} \mathrm{G} 3=\mathrm{Ala}+$ His.Gln (plasma concentrations of both AA) + Asn.Ser (plasma concentrations of both AA) + Pro; G1 = Val + Ile + Leu; $\mathrm{G} 2=\mathrm{Tyr}+$ Phe .

intake of the $7 \mathrm{AA}$ supplemented in the study differed $(P<0.001)$ among treatment groups. Proline intake was the greatest in PG calves $(22.8 \pm 0.36 \mathrm{~g} / \mathrm{d})$, followed by CTRL and FY calves $(20.8 \pm 0.36 \mathrm{~g} / \mathrm{d})$, and lowest in KMT calves $(19.8 \pm 0.40 \mathrm{~g} / \mathrm{d})$. Glycine intake was greater in PG $(9.2 \pm 0.26 \mathrm{~g} / \mathrm{d})$ than in KMT and FY calves $(8.2 \pm 0.28 \mathrm{~g} / \mathrm{d})$, and similar to CTRL calves $(8.7 \pm 0.27 \mathrm{~g} / \mathrm{d})$. Tyrosine and Phe intakes were greater in FY $(10.8 \pm 0.20$ and $13.6 \pm 0.29 \mathrm{~g} / \mathrm{d}$, respectively $)$ than in the other treatments $(9.8 \pm 0.21$ and $11.9 \pm$ $0.29 \mathrm{~g} / \mathrm{d}$, respectively). Threonine intake was greater in KMT $(16.4 \pm 0.26 \mathrm{~g} / \mathrm{d})$ than in the other treatments $(13.9 \pm 0.24 \mathrm{~g} / \mathrm{d})$, and Lys and Met intake was the greatest in KMT calves $(23.7 \pm 0.40$ and $5.9 \pm$ $0.08 \mathrm{~g} / \mathrm{d}$, respectively), followed by CTRL $(22.4 \pm 0.36$

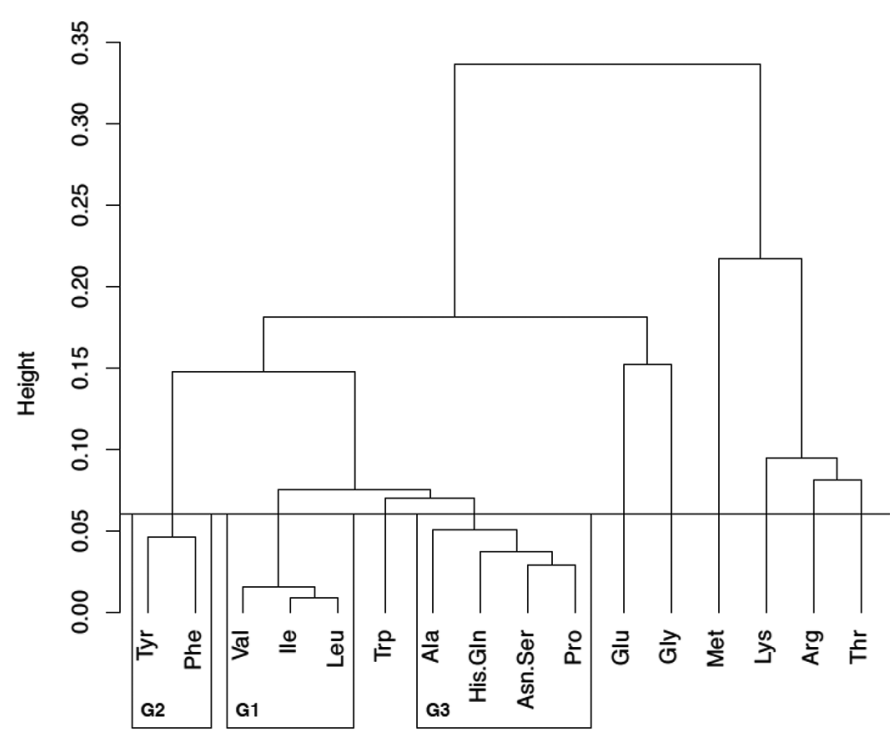

Figure 1. Cluster dendrogram of plasma AA composition, showing groups $(\mathrm{G}) 1,2$, and 3 .

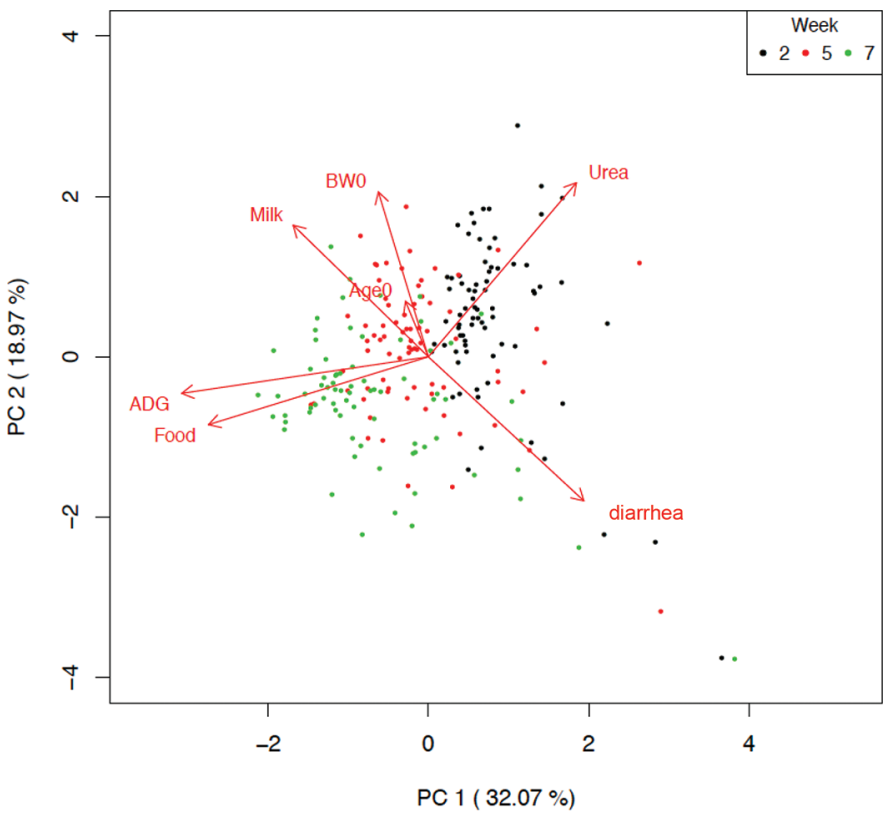

Figure 2. Principal component (PC) analysis biplot of performance, intake, and serum urea concentration data set of calves fed milk replacer with different AA composition at 2, 5, and 7 wk of study based on the correlation matrix. Food $=$ weekly average concentrate of DM feed intake; milk = weekly average milk DMI; BW0 = initial BW; urea $=$ semen urea concentration $(\mathrm{mg} / \mathrm{dL})$; diarrhea $=$ the number of days with diarrhea within a week (score 2 and 3 ).

and $5.1 \pm 0.07 \mathrm{~g} / \mathrm{d}$, respectively), and lowest in $\mathrm{PG}$ and FY treatments $(20.3 \pm 0.36$ and $4.8 \pm 0.07 \mathrm{~g} / \mathrm{d}$, respectively).

The PCA highlighted 2 main components accounting together for more than $52 \%$ of the variance observed in all calves (Figure 2). The first principal component captured the variability of ADG and the quantity of solid feed intake, and the second principal component mainly referred to serum urea concentrations and number of days with diarrhea. Thus, the first dimension captured animal growth, with those calves with better performance placed at the left of the plot, and the second accounted for factors limiting growth, with calves with impaired growth spread far from the center of the plot depending on the factor (elevated serum urea levels or digestive disorders).

\section{Compositional Analysis of Plasma Amino Acid Concentrations}

Descriptive statistics of plasma AA concentrations are depicted in Supplemental Table S2 (https://doi. org/10.34810/data41). Table 3 was constructed to study the codependence structure of plasma AA composition. It shows the sample center (closure of the geometric means) in the first row, the pairwise log-ratio 
variances of the $\mathrm{AA}$ in the upper triangle, and the logratio means in the lower triangle. Glycine, His plus Gln, and $\mathrm{Thr}$ were the AA with the greatest plasma relative concentrations, whereas the ones with lowest relative proportions were Met and Trp, as indicated by the greatest values of sample center. The upper triangle of Table 3 shows that Met and Gly were the 2 AA bearing the greatest contribution to the total variability of AA. In contrast, the branched-chain AA (Ile, Leu, Val) had a small variance among them, indicating that they were highly proportional to each other, and they could be grouped together for subsequent analysis. The relationships depicted in Table 3 were further used to construct the dendrogram.

The dendrogram allowed us to identify (at a height of 0.06) 3 clear groups of AA that could be clustered, before branched-chained AA were grouped within another AA cluster (Figure 1). The 3 branched-chain AA were the first to join into a single cluster. The second cluster, which was tightly composed, consisted of Ala, His/ Gln, and Asn/Ser; and Pro and Phe and Tyr were also grouped in the dendrogram. After grouping the initial 16 plasma AA proportions, the final AA composition was reduced to 10 components, which allowed us to create 9 balances with fairly interpretable coefficients (Table 4).

Calves fed KMT were clearly identified in the first principal component (Figure 3A) because Met, Lys, and Thr proportions in plasma were greater compared with the other treatments. Similarly, plasma Phe and Tyr proportions in plasma increased in FY calves compared with the other treatments (Figure 3B), but other AA were in line with the tendencies of the other MR. The centered log-ratio coefficient for Gly was always indicating calves in the PG treatment, and they were also characterized by slightly larger quantities of Glu and branched-chain AA. On the other hand, no AA from the biplots could be highlighted to identify calves fed the CTRL milk replacer.

The evolution of plasma AA composition over the different weeks of the study indicated that the proportion of plasma branched-chain AA, and His plus Gln, increased progressively along the sampling weeks. Conversely, plasma proportions of Thr, Arg, Lys, and Glu decreased during the study, whereas the rest of the AA were similarly balanced throughout the study. Plasma Arg proportions were affected by an interaction between treatment and sampling week, which resulted in an increased plasma Arg concentration at $7 \mathrm{wk}$ of study in KMT calves, whereas, in the other treatments, plasma Arg concentrations decreased progressively with age (data not shown).
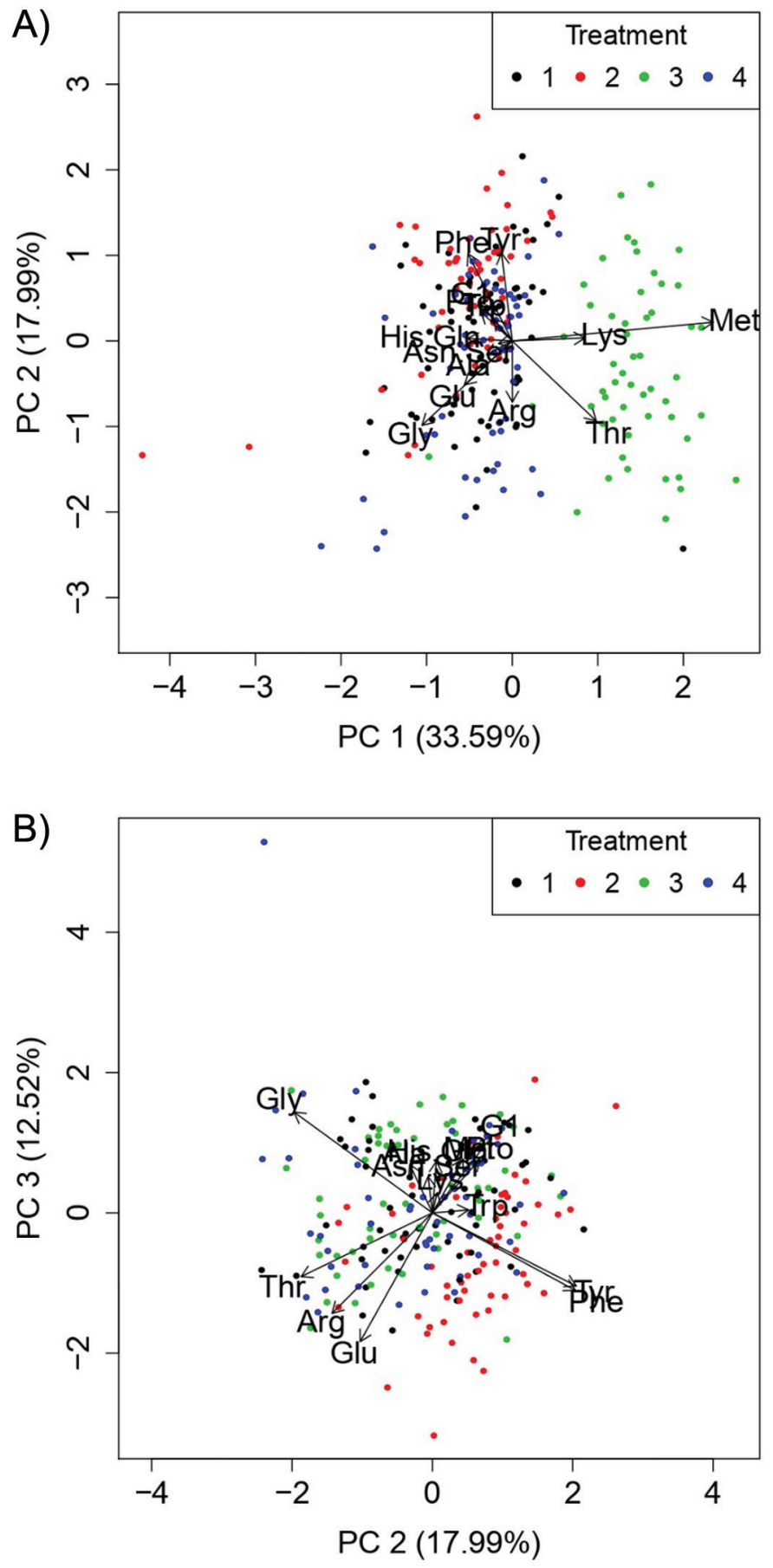

Figure 3. Compositional biplot of first and second dimension (A) and second and third dimension (B) of plasma AA compositional analysis from calves fed MR with different AA composition. Treatments: $1=$ PG, milk replacer supplying additional $0.3 \%$ Pro and $0.1 \%$ Gly; 2 $=\mathrm{FY}$, milk replacer supplying additional $0.2 \%$ Phe and $0.2 \%$ Tyr; $3=$ KMT, milk replacer providing additional $0.62 \%$ Lys, $0.22 \%$ Met, and $0.61 \%$ Thr; $4=$ CTRL, milk replacer with no AA supplementation. $\mathrm{PC}=$ principal component 
Table 5 indicates that the different MR offered in the study did not explain the variation in ADG or serum urea concentration, and none of the MR improved growth. However, both intake of concentrate and intake of MR were positively correlated with ADG, and the incidence of diarrhea was negatively related to calf growth, suggesting that those animals that ate all the concentrate feed offered and those that did not suffer any digestive health disorders were the ones with better performance, independent of their MR treatment.

We obtained balances of AA from a hierarchical clustering algorithm (see Table 4), and we used these balances as predictors in 2 mixed-effects models with ADG (Supplemental Table S3; https://doi.org/10.34810/ data42) and urea (Supplemental Table S4; https:// doi.org/10.34810/data43) as response variables. We removed nonsignificant balances by backward elimination, using a standard significance level of $5 \%$, while monitoring model fit statistics comparing Akaike's information criterion, Bayesian information criterion, and residual variance across models. Supplemental Tables S3 and S4 show the sequence of models obtained by backward selection for ADG and urea, respectively. The inclusion of the significant balances in the final models accounted for a reduction of Akaike's information criterion from -28.19 and 1,215.4 (without balances) to -45.58 and 1,165.19 (with significant balances) for the ADG and urea model, respectively. Residuals of the final model were normally distributed. The balances $b_{2}$ and $b_{3}$ were negatively correlated, and the balance $b_{5}$ was positively correlated with growth. Serum urea concentration decreased with week of study and increased with greater initial $\mathrm{BW}$, and balances $b_{1}$ and $b_{5}$ were negatively correlated with serum urea concentration, whereas balance $b_{8}$ was positively correlated with serum urea concentration.

\section{DISCUSSION}

The PCA conducted herein emphasized the importance of stimulating solid feed intake and avoiding health disorders to use protein efficiently and to promote calf growth. Methionine is considered to be one of the most limiting AA for dairy calves (Hill et al., 2007), and it may explain why the exploratory analysis of AA pointed to Met as 1 of the 2 AA contributing most to the total variability of plasma AA. The other AA largely contributing to AA plasma variability was

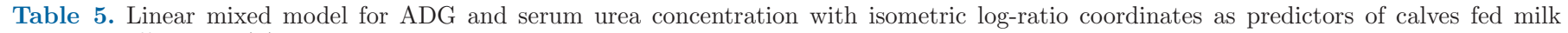
replacers differing in AA composition

\begin{tabular}{|c|c|c|c|c|c|c|}
\hline \multirow[b]{2}{*}{ Item $^{1}$} & \multicolumn{3}{|c|}{$\mathrm{ADG}$} & \multicolumn{3}{|c|}{ Serum urea concentration } \\
\hline & Estimate & SEM & $P$-value & Estimate & SEM & $P$-value \\
\hline Intercept & -0.377 & 0.511 & $>0.05$ & 19.471 & 8.493 & $<0.05$ \\
\hline Week & 0.036 & 0.014 & $<0.01$ & -0.723 & 0.239 & $<0.01$ \\
\hline Concentrate feed intake, $\mathrm{kg} / \mathrm{d}$ & 0.424 & 0.079 & $<0.01$ & -2.289 & 1.390 & $>0.05$ \\
\hline Milk replacer intake, $\mathrm{kg} / \mathrm{d}$ & 1.595 & 0.544 & $<0.01$ & -4.226 & 9.215 & $>0.05$ \\
\hline Serum urea, $\mathrm{mg} / \mathrm{dL}$ & -0.005 & 0.004 & $>0.05$ & - & - & - \\
\hline Diarrhea $^{2}$ & -0.032 & 0.014 & $<0.05$ & -0.284 & 0.235 & $>0.05$ \\
\hline Initial age, $\mathrm{d}$ & -0.005 & 0.007 & $>0.05$ & 0.105 & 0.144 & $>0.05$ \\
\hline Initial BW, kg & -0.001 & 0.002 & $>0.05$ & 0.160 & 0.042 & $<0.01$ \\
\hline FY supplement & -0.088 & 0.041 & $<0.05$ & -0.894 & 0.711 & $>0.05$ \\
\hline KMT supplement & -0.005 & 0.034 & $>0.05$ & 0.253 & 0.849 & $>0.05$ \\
\hline PG supplement & 0.033 & 0.033 & $>0.05$ & 1.062 & 0.714 & $>0.05$ \\
\hline$b_{1}$ & - & - & - & -8.100 & 2.298 & $<0.01$ \\
\hline$b_{2}$ & -0.236 & 0.072 & $<0.01$ & - & - & - \\
\hline$b_{3}$ & -0.353 & 0.084 & $<0.01$ & - & - & - \\
\hline$b_{4}$ & - & - & & - & - & - \\
\hline$b_{5}$ & 0.195 & 0.067 & $<0.01$ & -4.741 & 1.262 & $<0.01$ \\
\hline$b_{6}$ & - & - & & - & - & - \\
\hline$b_{7}$ & - & - & & - & - & - \\
\hline$b_{8}$ & - & - & & 1.924 & 0.930 & $<0.05$ \\
\hline$b_{9}$ & - & - & & - & - & - \\
\hline$\hat{\sigma}_{\varepsilon}$ & 0.176 & & & 2.835 & & \\
\hline$\hat{\sigma}_{u}$ & 0.011 & & & 1.420 & & \\
\hline$\hat{\rho}$ & 0.004 & & & 0.200 & & \\
\hline
\end{tabular}

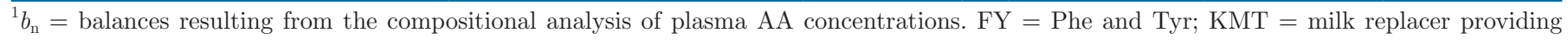

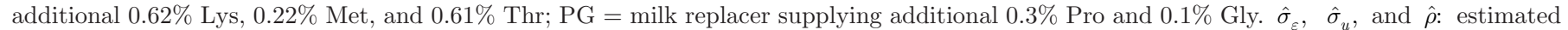
$\mathrm{SD}$ of the error term, estimated SD of the random effect, and estimated intraclass correlation coefficient, respectively.

${ }^{2}$ Number of days with diarrhea per week. 
Gly, which could be attributed to the fact that Gly is released in degradative pathways of various AA (Gerrits et al., 1998; Wang et al., 2013). Regarding the MR treatments, those treatments supplemented with essential AA (KMT and FY) clearly resulted in an increase of the supplemented AA in plasma relative concentrations, as also observed when calves were supplemented with Leu or Phe (or both) in other MR studies (Cao et al., 2018). In contrast, PG calves that were supplemented with nonessential AA showed only a slightly increase of plasma Gly proportion in their AA composition, together with plasma branched-chain AA and Gln. Probably Pro supplementation is responsible for the alignment of these AA in PG calves. Glutamine can act as a precursor of Pro (Wu et al., 2011), and Gln, Pro, and branched-chain AA are gut oxidative substrates (Wu, 1998). Then, the additional Pro may have been used as a gut oxidative substrate, and the metabolism of Gln and branched-chain AA in the gut may have been reduced, as Burrin and Stoll (2009) reported when an increase of gut oxidative substrates reduced gut metabolism of branched-chain AA. Probably CTRL calves were not clearly grouped in the compositional biplots because their AA profile in the MR did not differ from the other treatments by more than $5 \%$.

The differences in the evolution of plasma AA composition observed throughout the different weeks cannot be elucidated with the data of the present study, but some reasons could be envisaged: (1) changes in the efficiency of utilization of some AA with calf age (Gerrits et al., 1998); (2) different AA profile of protein reaching the small intestine as the proportion of microbial protein increases with calf age, as microbial protein is richer in Ala, Asp, Gly, Phe, Tyr, and Arg and poorer in Glu, His, Leu, Lys, and Pro compared with MR AA composition (Sok et al., 2017); and (3) different tissue needs as the calf develops (Gerrits et al., 1998).

The clusters defined to create AA composition balances (Figure 1) for further use in a mixed-effects model were reasonable, because branched-chain AA share metabolic pathways (Holeček, 2018), Phe is a precursor of Tyr, and the third cluster grouped nonessential AA. The balance will probably change because many factors influence plasma AA profile, such as dietary AA profile, microbial protein contribution, sampling time relative to feeding, and others. In fact, data obtained from calves that were fed an MR containing the same ingredients as the ones used herein, but differing in the AA profile (it was richer in Leu and Thr), were analyzed using the same statistical approach as in the current study, and although not all AA were grouped similarly, several of those identified herein were also present, such as Phe and Tyr, Thr and Arg, BCAA, and most of the NEAA. Calves in the present study were fed an MR containing skim milk and whey protein, and we had no intention to provoke any AA deficiency (Tzeng and Davis, 1980), with at least one of the treatments directed to achieve the values recommended in recent literature (Hill et al., 2008). The compositional analysis performed focused on the relationship among all the AA instead of a dose-effect for single AA, considering AA profile as the parameter to be evaluated. The use of AA balances suggested that instead of focusing on a specific limiting AA for calf growth, evaluating the relationship of the ratios among some of them seems to be more coherent. Among the balances included in the linear mixed-effects model, balance $b_{5}$, formed by Arg, Thr, and Lys, was positively correlated in the model exploring ADG, at the same time that it was negatively correlated in the serum urea concentration model independent of the week of study, suggesting that achieving an increase of the proportion of Arg and Thr with respect to Lys in plasma might help to synthesize protein more efficiently and improve growth. A metabolic relationship among the $3 \mathrm{AA}$ involved in $b_{5}$ has been reported in chicks (Austic and Scott, 1975). In chickens, a Lys-Arg antagonism exists, wherein an excess of dietary Lys increases Arg requirements, whereas Thr is an AA that prevents induction of arginase activity by Lys. However, this antagonist effect between Arg and Lys has not been demonstrated in young calves (Abe et al., 2001).

\section{CONCLUSIONS}

The use of compositional methods combined with model selection for mixed-effects models to analyze amino acid compositional data through isometric logratios identified a balance among 3 amino acids (arginine, threonine, and lysine) as being responsible for improving performance in preweaned calves under the conditions of the present study using a high-protein milk replacer with an amino acid profile similar to that found in whole milk.

\section{ACKNOWLEDGMENTS}

This research was supported by the Spanish Ministry of Economy and Competitivity (AGL2015-68463-C21-P and AGL2015-68463-C2-2-) and by grant RTI2018095518-B-C22 (MCIU/AEI/FEDER) of the Spanish Ministry of Science, Innovation and Universities and the European Regional Development Fund. We also thank Jordi Casino, Clara Jiménez, and Alex Campre- 
ciós from IRTA for their help with calf management and care. The authors have not stated any conflicts of interest.

\section{REFERENCES}

Abe, M., T. Iriki, K. Kaneshige, K. Kuwashima, S. Watanabe, H. Sato, and M. Funaba. 2001. Adverse effects of excess lysine in calves. J. Anim. Sci. 79:1337-1345. https://doi.org/10.2527/2001.7951337x.

Ahangarani, M. A., A. Bach, A. Bassols, M. Vidal, D. Valent, S. RuizHerrera, and M. Terré. 2020. Short Communication: Performance, intestinal permeability, and metabolic profile of calves fed a milk replacer supplemented with glutamic acid. J. Dairy Sci. 103:433438. https://doi.org/10.3168/jds.2019-17077.

Aitchison, J. 1986. The statistical analysis of compositional data. In Monographs on Statistics and Applied Probability. Chapman and Hall Ltd. (reprinted in 2003, with additional material, by the Blackburn Press).

AOAC International. 1999. Official Methods of Analysis. 16th ed. AOAC International.

AOAC International. 2000. Official Methods of Analysis. 17th ed. AOAC International.

Austic, R. E., and R. L. Scott. 1975. Involvement of food intake in the lysine-arginine antagonism in chicks. J. Nutr. 105:1122-1131. https://doi.org/10.1093/jn/105.9.1122.

Bai, Y., T. Liu, K. Hultquist, J. Wu, and D. P. Casper. 2020. Feeding an amino acid formulated milk replacer for Holstein calves. J. Anim. Sci. 98:skaa099. https://doi.org/10.1093/jas/skaa099.

Bhutia, Y. D., and V. Ganapathy. 2018. Protein digestion and absorption. In Physiology of the Gastrointestinal Tract. 6th ed. H. M. Said, ed. Academic Press. https://doi.org/10.1016/C2015-1-04889 $-\mathrm{X}$.

Brosnan, J. T. 2003. Interorgan amino acid transport and its regulation. J. Nutr. 133:2068S-2072S. https://doi.org/10.1093/jn/133.6 .2068S.

Burrin, D. G., and B. Stoll. 2009. Metabolic fate and function of dietary glutamate in the gut. Am. J. Clin. Nutr. 90(Suppl.):850S856S. https://doi.org/10.3945/ajcn.2009.27462Y.

Cao, Y. C., X. J. Yang, L. Guo, C. Zheng, D. D. Wang, C. J. Cai, S. M. Liu, and J. H. Yao. 2018. Effects of dietary leucine and phenylalanine on pancreas development, enzyme activity, and relative gene expression in milk-fed Holstein dairy calves. J. Dairy Sci. 101:4235-4244. https://doi.org/10.3168/jds.2017-13987.

Castro, J. J., G. H. Hwang, A. Saito, D. A. Vermeire, and J. K. Drackley. 2016. Assessment of the effect of methionine supplementation and inclusion of hydrolyzed wheat protein in milk proteinbased milk replacers on the performance of intensively fed Holstein calves. J. Dairy Sci. 99:6324-6333. https://doi.org/10.3168/ jds.2015-10639.

Ceballos, L. S., E. R. Morales, G. de la Torre Adarve, J. D. Castro, L. P. Martínez, and M. R. S. Sampelayo. 2009. Composition of goat and cow milk produced under similar conditions and analyzed by identical methodology. J. Food Compos. Anal. 22:322-329. https:/ /doi.org/10.1016/j.jfca.2008.10.020.

Chagas, J. C. C., M. A. Ferreira, A. P. Faciola, F. S. Machado, M. M. Campos, M. R. Entjes, J. L. Donzele, and M. I. Marcondes. 2018. Effects of methionine plus cysteine inclusion on performance and body composition of liquid-fed crossbred calves fed a commercial milk replacer and no starter feed. J. Dairy Sci. 101:6055-6065. https://doi.org/10.3168/jds.2017-13615.

Gerrits, W. J. J., J. W. Schrama, and S. Tamminga. 1998. The marginal efficiency of utilization of all ileal digestible indispensable amino acids for protein gain is lower than $30 \%$ in preruminant calves between 80 and 240 of live weight. J. Nutr. 128:1774-1785. https://doi.org/10.1093/jn/128.10.1774.

Hill, T. M., J. M. Aldrich, R. L. Schlotterbeck, and H. G. Bateman II.. 2007. Amino acids, fatty acids, and fat sources for calf milk replacer. The Professional Anim. Scientist 23:401-408. https://doi .org/10.15232/S1080-7446(15)30995-5.
Hill, T. M., H. G. Bateman II, J. M. Aldrich, R. L. Schlotterbeck, and K. G. Tanan. 2008. Optimal concentrations of lysine, methionine, and threonine in milk replacers for calves less than five weeks of age. J. Dairy Sci. 91:2433-2442. https://doi.org/10.3168/jds.2007 -0610 .

Holeček, M. 2018. Branched-chain amino acids in health and disease: Metabolism, alterations in blood plasma, and as supplements. Nutr. Metab. (Lond.) 15:33. https://doi.org/10.1186/s12986-018 -0271-1.

Kimura, T., Y. Noguchi, N. Shikata, and M. Takahashi. 2009. Plasma amino acid analysis for diagnosis and amino acid-based metabolic networks. Curr. Opin. Clin. Nutr. Metab. Care 12:49-53. https:// doi.org/10.1097/MCO.0b013e3283169242.

Li, P., and G. Wu. 2018. Roles of dietary glycine, proline, and hydroxyproline in collagen synthesis and animal growth. Amino Acids 50:29-38. https://doi.org/10.1007/s00726-017-2490-6.

Morrison, S. Y., J. M. Campbell, and J. K. Drackley. 2017. Amino acid supplementation of calf milk replacers containing plasma protein. J. Dairy Sci. 100:4637-4649. https://doi.org/10.3168/jds .2016-12402.

NRC. 2001. Nutrient Requirements of Dairy Cattle. 7th rev. ed. Natl. Acad. Press.

Palarea-Albaladejo, J., J. A. Rooke, I. M. Nevison, and R. J. Dewhurst. 2017. Compositional mixed modeling of methane emissions and ruminal volatile fatty acids from individual cattle and multiple experiments. J. Anim. Sci. 95:2467-2480. https://doi.org/ 10.2527/jas.2016.1339.

Pinheiro, J., and D. Bates. 2000. Mixed-Effects Models in S and SPLUS. Springer. https://doi.org/10.1007/b98882.

R Core Team. 2020. R: A Language and Environment for Statistical Computing. R Foundation for Statistical Computing. https://www .R-project.org/.

Regmi, N., T. Wang, M. A. Crenshaw, B. J. Rude, G. Wu, and S. F. Liao. 2016. Effects of dietary lysine levels on plasma free amino acid profile in late-stage finishing pigs. Springerplus 5:888. https:/ /doi.org/10.1186/s40064-016-2463-3.

Rius, A. G., H. A. Weeks, J. Cyriac, R. M. Akers, B. J. Bequette, and M. D. Hanigan. 2012. Protein and energy intakes affected amino acid concentrations in plasma, muscle, and liver, and cell signaling in the liver of growing dairy calves. J. Dairy Sci. 95:1983-1991. https://doi.org/10.3168/jds.2011-4688.

Robertson, J. B., and P. J. Van Soest. 1981. The detergent system of analysis. Chapter 9, pages 123-158, in The Analysis of Dietary Fiber in Food. W. P. T. James and O. Theander, ed. Marcel Dekker.

Shikata, N., Y. Maki, Y. Noguchi, M. Mori, T. Hanai, M. Takahashi, and M. Okamoto. 2007. Multi-layered network structure of amino acid (AA) metabolism characterized by each essential AA-deficient condition. Amino Acids 33:113-121. https://doi.org/10.1007/ s00726-006-0412-0.

Sok, M., D. R. Ouellet, J. L. Firkins, D. Pellerin, and H. Lapierre. 2017. Amino acid composition of rumen bacteria and protozoa in cattle. J. Dairy Sci. 100:5241-5249. https://doi.org/10.3168/ jds.2016-12447.

Tzeng, D., and C. L. Davis. 1980. Amino acid nutrition of the young calf. Estimation of methionine and lysine requirements. J. Dairy Sci. 63:441-450. https://doi.org/10.3168/jds.S0022-0302(80)82951 -1 .

UNE. 2005a. Animal feeding stuffs. Determination of amino acids content. ISO13903:2005. UNE.

UNE. 2005b. Animal feeding stuffs. Determination of tryptophan content. ISO:13904:2005. UNE.

Urie, N. J., J. E. Lombard, C. B. Shivley, C. A. Kopral, A. E. Adams, T. J. Earleywine, J. D. Olson, and F. B. Garry. 2018. Preweaned heifer management on US dairy operations: Part I. Descriptive characteristics of preweaned heifer raising practices. J. Dairy Sci. 101:9168-9184. https://doi.org/10.3168/jds.2017-14010.

Van Soest, P. J., J. B. Robertson, and B. A. Lewis. 1991. Methods for dietary fiber, neutral detergent fiber, and nonstarch polysaccharides in relation to animal nutrition. J. Dairy Sci. 74:3583-3597. https://doi.org/10.3168/jds.S0022-0302(91)78551-2. 
Wang, W., Z. Wu, Z. Dai, Y. Yang, J. Wang, and G. Wu. 2013. Glycine metabolism in animals and humans: Implications for nutrition and health. Amino Acids 45:463-477. https://doi.org/10.1007/ s00726-013-1493-1.

Wu, G. 1998. Intestinal mucosal amino acid catabolism. J. Nutr. 128:1249-1252. https://doi.org/10.1093/jn/128.8.1249.

Wu, G. 2014. Dietary requirements of synthesizable amino acids by animals: A paradigm shift in protein nutrition. J. Anim. Sci. Biotechnol. 5:34. https://doi.org/10.1186/2049-1891-5-34.

Wu, G., F. W. Bazer, R. C. Burghardt, G. A. Johnson, S. W. Kim, D. A. Knabe, P. Li, X. Li, J. R. McKnight, M. C. Satterfield, and T. E. Spencer. 2011. Proline and hydroxyproline metabolism: implications for animal and human nutrition. Amino Acids 40:1053-1063. https://doi.org/10.1007/s00726-010-0715-z.

Wu, G., F. W. Bazer, Z. Dai, D. Li, J. Wang, and Z. Wu. 2014. Amino acid nutrition in animals: Protein synthesis and beyond. Annu. Rev. Anim. Biosci. 2:387-417. https://doi.org/10.1146/annurev -animal-022513-114113.

Yu, K., M. Matzapetakis, D. Valent, Y. Saco, A. M. De Almeida, M. Terré, and A. Bassols. 2018. Skeletal muscle metabolomics and blood biochemistry analysis reveal metabolomic changes associated with dietary amino acid supplementation in dairy calves. Sci. Rep. 8:13850. https://doi.org/10.1038/s41598-018-32241-4.

Yvon, M., J. P. Pélissier, P. Guilloteau, and R. Toullec. 1985. In vivo milk digestion in the calf abomasum. III. Amino acid compositions of the digesta leaving the abomasum. Reprod. Nutr. Dev. 25:495-504. https://doi.org/10.1051/rnd:19850402.

\section{ORCIDS}

M. Terré $\odot$ https://orcid.org/0000-0002-2815-9035

I. Ortuzar (ㄴ) https://orcid.org/0000-0002-3371-6633

J. Graffelman (1) https://orcid.org/0000-0003-3900-0780

A. Bassols @ https://orcid.org/0000-0003-4213-2274

A. Bach (1) https://orcid.org/0000-0001-6804-2002 